\title{
Motor and non-motor outcomes in patients with advanced Parkinson's disease treated with levodopa/carbidopa intestinal gel: final results of the GREENFIELD observational study
}

\author{
Leonardo Lopiano ${ }^{1}$. Nicola Modugno ${ }^{2}$. Pietro Marano ${ }^{3}$ Mariachiara Sensi ${ }^{4}$. Giuseppe Meco ${ }^{5}$ Paolo Solla ${ }^{6}$. \\ Graziano Gusmaroli $^{7}$. Filippo Tamma ${ }^{8} \cdot$ Francesca Mancini $^{9} \cdot$ Rocco Quatrale $^{10} \cdot$ Roberta Zangaglia $^{11}$. \\ Annarita Bentivoglio $^{12,13} \cdot$ Roberto Eleopra $^{14} \cdot$ Giuliana Gualberti $^{15} \cdot$ Gabriella Melzi $^{15}$ - Angelo Antonini ${ }^{16}$
}

Received: 22 January 2019 / Revised: 18 April 2019 / Accepted: 23 April 2019 / Published online: 27 May 2019

(c) The Author(s) 2019

\begin{abstract}
Introduction The GREENFIELD observational study assessed the effect of levodopa/carbidopa intestinal gel (LCIG) on motor and non-motor symptoms, and the related impact on patient quality of life and caregiver burden up to 8 years.

Methods Final results of a large Italian cohort of patients who started LCIG in routine care between 2007 and 2014 are presented. Comparison between baseline (before LCIG) and follow-up visits on yearly basis (visit 2/3) is reported. Primary endpoint was Unified Parkinson's Disease Rating Scale (UPDRS-IV) Item 39; secondary endpoints were UPDRS I and II, dyskinesia items, PD Quality of Life Questionnaire-39, Parkinson's Disease Sleep Scale-2, Gait and Falls Questionnaire, Questionnaire on Impulsive Disorders, and Relative Stress Scale.

Results Overall, 145 patients from 14 centers were assessed with a mean time since LCIG start of $2.8 \pm 1.7$ years at visit 2. The mean UPDRS-IV item 39 score showed significant reductions compared to baseline (mean score $2.0 \pm 0.81$ ) at visit 2 (mean score $0.9 \pm 0.69 ;-55 \% ; p<0.001$ ) and at visit 3 (mean score $1.0 \pm 0.75 ;-50 \% ; p<0.001$ ). At visit 3 , significant reductions were observed for dyskinesia duration score $(-28 \% ; p<0.001)$, dyskinesia disability $(-40 \% ; p<0.001)$, and painful dyskinesia $(-50 \% ; p<0.001)$. Overall, $40(27.6 \%)$ patients experienced 49 serious adverse events which were considered related to PEG/J procedure or to device in $16.3 \%$ of the cases.

Conclusions The results of this study support the long-term efficacy of LCIG on PD symptoms as well as on activities of daily living. The adverse events were consistent with the established LCIG safety profile.
\end{abstract}

Keywords Advanced Parkinson's disease · Levodopa/carbidopa · Intestinal infusion · Motor symptoms · Quality of life · Routine patient care

\section{Introduction}

Parkinson's disease (PD) is a chronic, progressive neurodegenerative disorder characterized by motor and non-motor symptoms that impair patient's autonomy and quality of life (QoL), together with a consequent burden also on caregiver QoL [1].

Electronic supplementary material The online version of this article (https://doi.org/10.1007/s00415-019-09337-6) contains supplementary material, which is available to authorized users.

Gabriella Melzi

gabriella.melzi@abbvie.com

Extended author information available on the last page of the article
Oral levodopa efficacy shortens as PD progresses; in fact, within 2-5 years up to $50 \%$ of patients already may experience some degree of motor complications, with $80-100 \%$ of PD patients developing motor complications after 10 years of dopaminergic therapy. This is mainly due to the progressive loss of striatal dopamine nerve terminals, the short levodopa half-life, the delayed gastric emptying and abnormal intestinal absorption [2-4].

Levodopa/carbidopa intestinal gel (LCIG) is continuously delivered via a percutaneous endoscopic gastrostomy with a jejunal extension (PEG-J) providing a more stable plasma concentration in patients with non-optimal control of motor fluctuations [5].

Initial evidence for the efficacy and tolerability of LCIG came from a number of small-sample studies.[6, 7]. 
Recently, three randomized clinical trials (RCTs) (one of them double blinded) have confirmed that LCIG reduced OFF time, increased ON time without increasing troublesome dyskinesias, and improved QoL [8-10]. The antidyskinetic effect of LCIG has been reported in the post hoc analyses of a 12-week double-blind study and of a 54-week open-label study on patients having at least $1 \mathrm{~h}$ per day of ON-time with troublesome dyskinesia [11]. Recently, a 6-month open-label pilot study, showing a $47 \%$ reduction of ON-time with troublesome dyskinesia, stated that LCIG has a substantial antidyskinetic effect and could be an alternative treatment also for PD patients with dyskinesia.[12]

Moreover, LCIG leads to significant improvements in motor and non-motor symptoms, in daily living activities and QoL also in patients with motor complications [13].

The long-term effectiveness of levodopa/carbidopa in APD patients on motor complications and QoL has been assessed in several routine clinical care studies up to 4 years of treatment duration [14-19]. Few studies have been conducted in large populations to assess the LCIG outcomes longer than 4 years [20,21]. Therefore, in the current study, we recorded the clinical outcomes in a large cohort of APD patients receiving LCIG in routine clinical care to evaluate the effects of therapy on both motor and non-motor symptoms, and the related impact on patient QoL and caregiver burden from the initiation of LCIG therapy over a maximum exposure period up to 8 years. The interim analysis of this study comparing the changes in primary endpoint and UPDRS scores between visit 1 (V1) and baseline (BL) data was previously published [22]. Here, we present the final results of this study.

\section{Patients and methods}

This post-marketing observational study was conducted in 14 Italian Movement Disorder Centers.

Treatment with LCIG was initiated in a routine patient care setting, according to the Summary of Product Characteristics, including the temporary naso-jejunal (NJ) phase to determine if the patient responded favorably to LCIG and to optimize the dose before treatment was initiated via PEG-J tube.

\section{Patient selection}

Consecutive APD patients showing motor fluctuations despite the use of oral medication, who started LCIG infusion according to clinical practice between 2007 and 2014, were considered eligible for enrollment into the study.

Inclusion criteria were: to be already treated with LCIG, presence of adequate information about previous medical history and treatment, and presence of at least one fulfilled scale or questionnaire among those collected during the study. Patients could be enrolled at any time after LCIG treatment initiation. Exclusion criteria were the presence of any conditions that, at the physician's discretion, could interfere with the long-term treatment with LCIG.

At the enrollment visit (V1), patient history and retrospective clinical data referred to previous conventional PD treatment, NJ phase and initiation of LCIG treatment via PEG-J were collected as BL data. During the same visit, current clinical parameters were also collected as V1 data. For the analysis, BL was defined as the last available data collected prior to $\mathrm{NJ}$ tube positioning.

\section{Study design and treatment}

The study design included two patient populations: the retrospective population and the prospective population. The retrospective population included all patients who had been receiving treatment with LCIG for $\geq 1$ year and up to 7 years before $\mathrm{V} 1$, with available $\mathrm{BL}$ retrospective assessment data for $\geq 1$ year. The prospective population included all patients receiving treatment with LCIG for $<1$ year before V1. Patients continuing with LCIG treatment for further 2 years after enrolment and with follow-up visits on yearly basis (visit 2, V2 and visit 3, V3 or at the last available visit) were included in the final analysis.

\section{Assessments}

\section{Effectiveness}

The primary endpoint was the change from baseline to the last available follow-up (V2 or V3 or the last available visit) in the item-39 of the UPDRS-IV (proportion of waking day spent in OFF).

At V1 (enrolment visit), the following baseline data for secondary effectiveness measures were collected: demographics, medical history, previous PD treatments, NJ phase, LCIG dose of infusion at discharge from the hospital; the Hoehn and Yahr scale; the UPDRS I total score (in ON and OFF conditions), activities of daily living (ADL), as assessed by means of the UPDRS II total score (in ON and OFF conditions), UPDRS IV (total score), and items for dyskinesia duration (Item 32), dyskinesia severity (Item 33), painful dyskinesia (Item 34), and early-morning dystonia (Item 35). At the same visit, PD Quality of Life Questionnaire (PDQ-39), Parkinson's Disease Sleep Scale (PDSS2), Gait and Falls Questionnaire (GFQ), Questionnaire on Impulsive Disorders (QUIP-RS), and the Relative Stress Scale (RSS) for caregiver burden assessment were collected only for patients in treatment with LCIG for more than 1 year before the enrolment visit and for all patients with missing $\mathrm{BL}$ value. 
The same assessments were repeated at V2 and at V3 including concurrent diseases and therapies, dosages and changes in LCIG daily infusion, and the economic and social impact of the familiar caregiver assistance. At each visit, the global efficacy on motor symptoms was rated by neurologist versus baseline by a three-point scale: improvement, no change, worsening. The patient's judgment on LCIG benefit, was collected at each visit by means of a scale rating from 0 to 10 and grouped as follows: $0-2$ very bad, 3-5 unsatisfactory, 6-8 satisfactory, 9-10 very good. Safety data were collected from enrolment visit onward.

\section{Safety}

Serious adverse events (SAE) were collected retrospectively at the enrolment visit (V1) and prospectively at each follow-up visit (V2 and V3). Adverse events (AE) were prospectively collected. Furthermore, all the Product Quality Complaints (PQC), with regard to the medical devices defined as communication that alleges deficiencies related to the identity, physical aspects, potency, expressed lack of effect, purity, packaging, durability, reliability, safety or performance, associated or not with an AE were retrospectively and prospectively collected.

\section{Statistical analysis}

\section{Sample size evaluation}

Postulating a correlation between values at baseline and at last follow-up $=0$ (conservative decision), a mean difference between baseline and last follow-up on the item 39 of UPDRS questionnaire of - 1.0, a SD of 2.0 and using a paired $t$ test, 87 subjects were to be enrolled, with twosided significance level $=5 \%$ and power $=90 \%$. Considering a drop-out rate of $40 \%$ (according to the Italian clinical experience: $22 \%$ of drop-outs $+18 \%$ of deaths should be considered), at least 145 subjects were needed; therefore, a total of 150 patients were estimated to be enrolled.

\section{Statistical analysis}

All statistical analyses were carried out by means of the SAS ${ }^{\circledR}$ package (version 9.2). Continuous and categorical variables were summarized by descriptive statistics. Statistical significance was declared if the rounded $p$ value was less than or equal to 0.05 .

All patients from enrolled population that performed at least one post-baseline visit (V2 or V3 for prospective patients, V1 or V2 or V3 for retrospective patients) were included in the evaluable population. All analyses of efficacy variables were performed in the evaluable population.
For assessments over time (e.g., for all rating scales), the analysis by visit (V1-V3) was complemented by an analysis according to the "last-observation-carried-forward" (LOCF) principle: missing data at $\mathrm{V} 3$ have been replaced with the (non-missing) data recorded at V2. No baseline value (at V1) has been considered in the LOCF technique.

Comparisons between BL and each follow-up visit (with LOCF) of the efficacy endpoints were performed using a paired $t$ test. Comparison between BL and each follow-up visit (with LOCF) of item 35 of UPDRS was performed by means of McNemar test. The same analysis was performed separately for the subgroups of prospective and retrospective patients. The comparison of the clinical indexes and the questionnaires scores during time was also confirmed through ANOVA for repeated measures on the population without LOCF.

To evaluate the impact of age of the patient and duration of disease on the UPDRS scores, a secondary analysis was performed by means of an analysis of covariance (ANCOVA) model with change from BL (with LOCF) as dependent variable, age of patient (dichotomous variable: $\leq 70$ years; $>70$ years), time since PD diagnosis (dichotomous variable: $\leq 13$ years; $>13$ years), and time since infusion ( $<1$ year vs $\geq 1$ year) as fixed effects and BL value as covariate. The difference between the adjusted means for age $\leq 70$ years versus $>70$ years and for time since PD diagnosis $\leq 13$ years versus $>13$ years were calculated with the associated $95 \% \mathrm{CI}$ and $p$ value.

\section{Results}

From the start of enrollment in November 2012 through July 2014, a total of 148 patients were included among the participating centers. Three subjects were excluded, due to inclusion/exclusion criteria violation, so the enrolled sample consists of 145 patients and 137 were evaluable. Across the study, 30 patients discontinued for different reasons and 115 patients completed the 24-month follow-up (Fig. 1). Considering that no differences in the primary and secondary efficacy measures were found between the retrospective $(N=59)$ and prospective populations ( $N=86 ; 78$ evaluable), we present here the results of the total population. In the total evaluable population, BL values were the data recorded before naso-jejunal phase or, if missing, data recorded at V1.

Demographic, medical history, occupational status, and previous advanced PD medications before the initiation of LCIG are summarized in Table 1. The mean age of patients $( \pm \mathrm{SD})$ was $70.4 \pm 7.7$ years, and the mean PD duration and the mean time since the onset of motor fluctuations were, respectively, $14.6 \pm 6.5$ and $5.9 \pm 3.9$ years. 


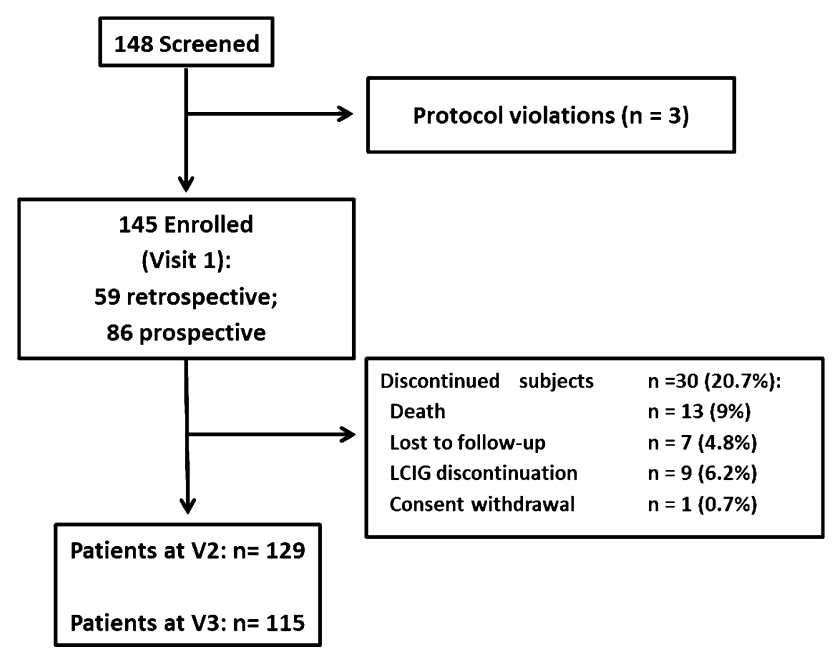

Fig. 1 Patient disposition

Table 1 Demographic and clinical characteristics of the study population

\begin{tabular}{|c|c|c|}
\hline Parameters & Value & Range \\
\hline Demographics & $n=145$ & \\
\hline \multicolumn{3}{|l|}{ Gender } \\
\hline Female, $n(\%)$ & $72(49.7 \%)$ & \\
\hline Male, $n(\%)$ & $73(50.3 \%)$ & \\
\hline Age (years) & $70.4 \pm 7.7$ & $49-90$ \\
\hline \multicolumn{3}{|l|}{ Age } \\
\hline$<65$ years, $n(\%)$ & $30(20.7 \%)$ & \\
\hline$\geq 65$ years, $n(\%)$ & $115(79.3 \%)$ & \\
\hline Age $>70$ years, $n(\%)$ & $78(53.8 \%)$ & \\
\hline \multicolumn{3}{|l|}{ PD medical history } \\
\hline Age at PD diagnosis (years) & $55.7 \pm 9.27$ & \\
\hline PD duration (years) & $14.61 \pm 6.58$ & $1.3-46.7$ \\
\hline$P D$ duration $\leq 13$ years & $72(49.7 \%)$ & \\
\hline PD duration $>13$ years & $73(50.3 \%)$ & \\
\hline $\begin{array}{l}\text { Time since onset of motor } \\
\text { fluctuations (years) } \\
(n=143)(\text { mean } \pm \text { SD) }\end{array}$ & $5.9 \pm 4.0$ & $1-21$ \\
\hline $\begin{array}{l}\text { Previous use of invasive } \\
\text { treatments (before LCIG } \\
\text { infusion) }\end{array}$ & $N(\%)$ & Daily dose, mean \pm SD \\
\hline $\begin{array}{l}\text { Previous deep brain stimula- } \\
\text { tion }\end{array}$ & $3(2.1 \%)$ & NA \\
\hline $\begin{array}{l}\text { Apomorphine SC (pump) } \\
\text { (mg) }\end{array}$ & $14(9.7 \%)$ & $86.29(46.38)$ \\
\hline Apomorphine stylo (mg) & 7 (4.8\%) & $6.5(10.6)$ \\
\hline
\end{tabular}

The antiparkinsonian medications with the daily dosages prior to start LCIG infusion are reported in Table 2; oral levodopa was the most commonly used antiparkinsonian medication (96.6\% of patients), at a mean daily dose of $818.17 \pm 404.4 \mathrm{mg}$.

The primary reasons to switch from oral antiparkinsonian therapy to LCIG were disabling OFF periods in 115 patients (79\%) and uncontrolled dyskinesia in 32 patients (25\%). At the last visit, the mean time since the LCIG start was $2.8 \pm 1.66$ years with a maximum treatment period of 8 years. The mean continuous infusion rate at the discharge from hospital was $3.21 \pm 1.09 \mathrm{ml} / \mathrm{h}$ and it remained stable at the following visits (respectively, $3.23 \pm 1.03$ and $3.31 \pm 1.28$ at V2 and V3). LCIG was infused for $16 \mathrm{~h}$ per day, while only one patient at V1 and three patients at V3 reported a 24-h infusion.

\section{Efficacy}

The mean UPDRS-IV item 39 score showed significant and sustained reductions at $\mathrm{V} 2$ compared to $\mathrm{BL}$ (mean BL score $2.0 \pm 0.81$, mean V2 score $0.9 \pm 0.69 ;-55 \% ; p<0.001)$ and also compared to V3 (mean score $1.0 \pm 0.75 ;-50 \%$; $p<0.001$ ), as reported in Fig. 2.

Furthermore, at each visit, respectively, $83 \%$ and $78 \%$ of the patients showed less than $25 \%$ of daily time spent in OFF while at BL the majority of them (76\%) had more than $25 \%$ of daily time in OFF (Fig. 3).

The mean LCIG treatment period at the primary endpoint assessment (V3) was $3.1 \pm 1.5$ years in the general population, while in the retrospective population the mean LCIG treatment period was $3.7 \pm 1.7$ years at V2 and $4.5 \pm 1.5$ years at $\mathrm{V} 3$.

At the last follow-up visit (V3), significant reductions compared to BL were observed for dyskinesia duration score ( $-28 \%$ UPDRS IV Item $32 ; p<0.001$ ), dyskinesia disability ( $-40 \%$ UPDRS IV Item $33 ; p<0.001$ ), and painful dyskinesia ( $-50 \%$ UPDRS IV Item $34 ; p<0.001)$ with a similar trend at each follow-up visit. The mean score reductions for each of the above-mentioned parameters and the corresponding $p$ values are reported in Table 3, along with the ANOVA results for repeated measures.

The UPDRS-IV (Part A + B) was significantly reduced compared to BL (mean baseline score 8.2 \pm 3.27 ) both at V2 (mean score $4.7 \pm 2.88 ; p<0.001$ ) and at V3 (mean score $4.9 \pm 3.12 ; p<0.001)$.

Twenty-five percent of the patients reported early morning dystonia (UPDRS IV Item 35) at V3 while this percentage was higher at BL ( $44 \%$ of the patients, $p<0.001$ ).

There was a significant improvement through the whole study duration, on UPDRS II in OFF state that was reduced from $29.2 \pm 9.63$ at BL to $25.7 \pm 8.49(p<0.001)$ at $\mathrm{V} 2$ and to $25.5 \pm 8.76$ at V3 $(p=0.003)$ (Table 3$)$. 
Table 2 Use of antiparkinsonian medications before and during LCIG at each visit

\begin{tabular}{|c|c|c|c|c|c|c|c|c|}
\hline \multirow{2}{*}{$\begin{array}{l}\text { Antiparkinso- } \\
\text { nian medica- } \\
\text { tions }\end{array}$} & \multicolumn{2}{|c|}{ Before LCIG start $(N=145)$} & \multicolumn{2}{|c|}{ Visit $1(N=145)$} & \multicolumn{2}{|c|}{ Visit $2(N=129)$} & \multicolumn{2}{|c|}{ Visit $3(N=115)$} \\
\hline & $N(\%)$ & $\begin{array}{l}\text { Daily } \\
\text { dose }(\mathrm{mg}) \\
\text { mean } \pm \mathrm{SD}\end{array}$ & $N(\%)$ & $\begin{array}{l}\text { Daily dose }(\mathrm{mg}) \\
\text { mean } \pm \mathrm{SD}\end{array}$ & $N(\%)$ & $\begin{array}{l}\text { Daily dose } \\
(\mathrm{mg}) \\
\text { mean } \pm \mathrm{SD}\end{array}$ & $N(\%)$ & $\begin{array}{l}\text { Daily dose }(\mathrm{mg}) \\
\text { mean } \pm \mathrm{SD}\end{array}$ \\
\hline Oral levodopa & $140(96.6 \%)$ & $818.74 \pm 404.4$ & $\begin{array}{l}5(3 \%)- \\
\text { during the } \\
\text { day } \\
34(23 \%)- \\
\text { at night }\end{array}$ & $\begin{array}{l}150.0 \pm 70.7 \\
\text { during the day } \\
160.3 \pm 72.5 \\
\text { at night }\end{array}$ & $\begin{array}{l}4(3 \%)- \\
\text { during the } \\
\text { day } \\
30(23 \%)- \\
\text { at night }\end{array}$ & $\begin{array}{l}475.0 \pm 518.8 \\
\text { during the day } \\
164.2 \pm 56.3 \\
\text { at night }\end{array}$ & $\begin{array}{l}4(3 \%)- \\
\text { during the } \\
\text { day } \\
30(26 \%)- \\
\text { at night }\end{array}$ & $\begin{array}{l}137.5 \pm 75.0 \\
\text { during the day } \\
186.7 \pm 73.0 \text { at } \\
\text { night }\end{array}$ \\
\hline $\begin{array}{l}\text { Dopamine } \\
\text { agonists }\end{array}$ & $93(64.1 \%)$ & $6.38 \pm 5.6$ & $42(29 \%)$ & $5.6 \pm 3.8$ & $39(30 \%)$ & $5.1 \pm 3.3$ & $28(24 \%)$ & $6.6 \pm 5.6$ \\
\hline $\begin{array}{l}\text { COMT inhibi- } \\
\text { tors }\end{array}$ & $64(44.1 \%)$ & $590.7 \pm 337.4$ & $16(11 \%)$ & $253.1 \pm 105.6$ & $16(12 \%)$ & $215.6 \pm 67.6$ & $14(12 \%)$ & $196.4 \pm 69.2$ \\
\hline MAO inhibitors & $21(14.5 \%)$ & $2.33 \pm 3.31$ & $5(3 \%)$ & $3.6 \pm 3.9$ & $5(4 \%)$ & $5.8 \pm 5.07$ & $5(4 \%)$ & $3.6 \pm 3.9$ \\
\hline Amantadine & $25(17.2 \%)$ & $190.6 \pm 112.6$ & $8(6 \%)$ & $237.5 \pm 91.6$ & $12(9 \%)$ & $200.0 \pm 95.3$ & $10(9 \%)$ & $220.0 \pm 113.5$ \\
\hline
\end{tabular}

Data presented in mean \pm standard deviation $(\mathrm{SD})$ or number $(\%)$

$L C I G$ levodopa/carbidopa intestinal gel, $P D$ Parkinson's disease, $S C$ subcutaneous

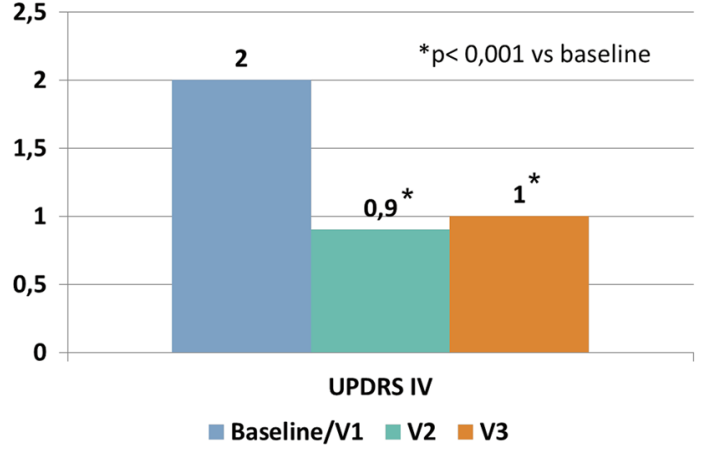

*: t-test vs baseline/V1; UPDRS: Unified Parkinson's Disease Rating Scale.

Fig. 2 UPDRS-Part IV mean subscores at baseline/V1 $(N=139)$, V2 $(N=129)$ and $\mathrm{V} 3(N=115)$

\section{Quality-of-life and PD-associated symptoms}

The results on QoL and PD-associated symptoms questionnaires at each visit showed a different behavior in the retrospective and prospective population. The prospective population performed the assessments both at BL (close to LCIG start) and at each follow-up visit, while most of the assessments were not performed close to LCIG start for the retrospective population. Therefore, we show in Table 4 the results of the prospective population and in Supplementary Table 1 those of the retrospective population.

The PDQ-39 showed significant improvements at V2 (mean score $64.7 \pm 25.4 ; p<0.001$ ) and at V3 (mean score $67.3 \pm 26.4 ; p<0.05$ ) compared to BL (mean score $72.3 \pm 23.8$ ) (Table 4).
Fig. 3 Distribution of UPDRSIV Item 39 at Visit 2 (V2) and Visit 3 (V3) compared to baseline or V1

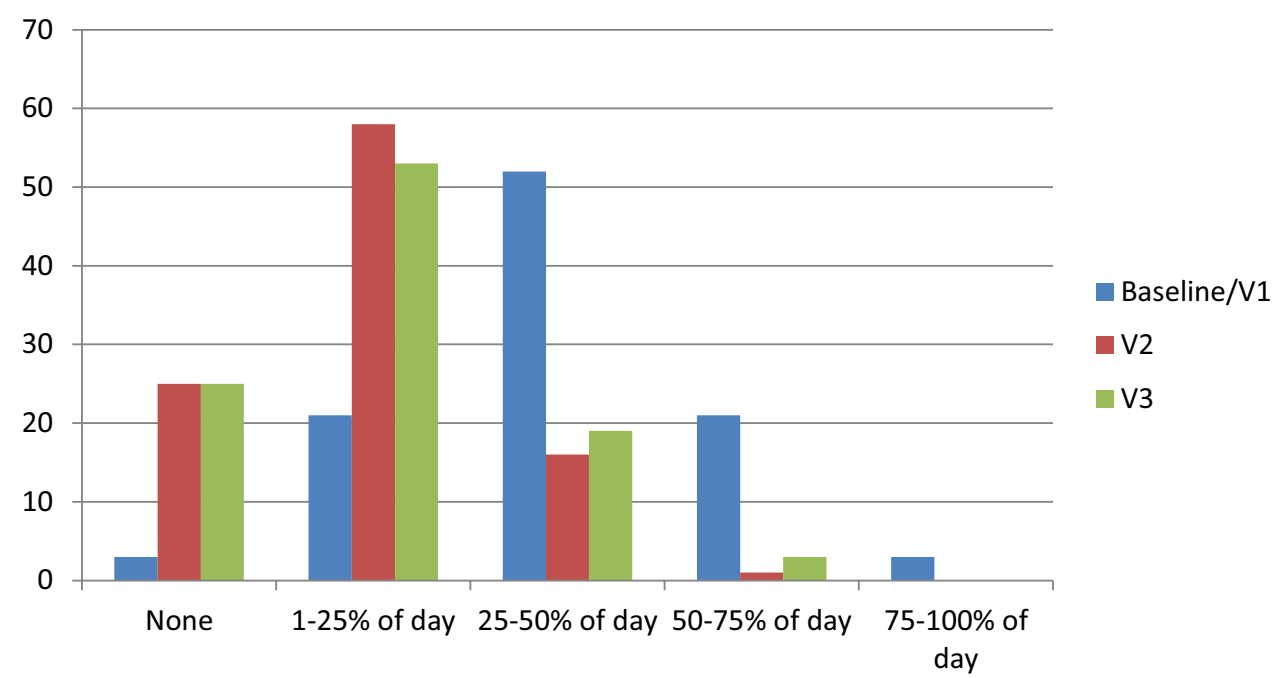


Table 3 Complications of therapy (UPDRS IV), UPDRS-I, ADL and H\&Y stage at baseline (before LCIG treatment) and at each follow-up visit, without LOCF

\begin{tabular}{|c|c|c|c|c|c|c|c|c|}
\hline $\begin{array}{l}\text { BL mean score } \\
( \pm S D)(\text { Range })\end{array}$ & $\mathrm{N}$ & Visit 2 & $\mathrm{~N}$ & Visit 3 & $\mathrm{~N}$ & $\begin{array}{l}\text { Reduction } \\
\text { at V3 vs } \\
\text { BL }\end{array}$ & $\begin{array}{l}* p \text { value at } \mathrm{V} 2 \\
\text { vs } \mathrm{BL} \\
* * p \text { value at } \mathrm{V} 3 \\
\text { vs } \mathrm{BL}\end{array}$ & $\begin{array}{l}p \text { ANOVA } \\
\text { for repeated } \\
\text { measures }\end{array}$ \\
\hline
\end{tabular}

\begin{tabular}{|c|c|c|c|c|c|c|c|c|}
\hline $\begin{array}{l}\text { UPDRS IV total } \\
\text { score (Items } \\
32-42 \text { ) }\end{array}$ & $8.2(3.27)(0-18) 134$ & $4.7(2.88)(0-14)$ & 124 & $4.9(3.12)(0-14)$ & 112 & $-40 \%$ & $\begin{aligned} * & <0.001 \\
& * *<0.001\end{aligned}$ & $<0.001$ \\
\hline $\begin{array}{l}\text { Dyskinesia dura- } \\
\text { tion (Item 32) }\end{array}$ & $1.8(1.04)(0-4) 134$ & $1.2(0.89)(0-4)$ & 127 & $1.3(1.02)(0-4)$ & 113 & $-28 \%$ & $\begin{aligned} * & <0.001 \\
& * *<0.001\end{aligned}$ & $<0.001$ \\
\hline $\begin{array}{l}\text { Dyskinesia dis- } \\
\text { ability (Item } \\
\text { 33) }\end{array}$ & $1.5(1.11)(0-4) 133$ & $0.9(1.02)(0-4)$ & 124 & $0.9(1.01)(0-4)$ & 112 & $-40 \%$ & $\begin{aligned} * & <0.001 \\
& * *<0.001\end{aligned}$ & $<0.001$ \\
\hline $\begin{array}{l}\text { Painful dyskine- } \\
\text { sia (Item 34) }\end{array}$ & $0.8(0.97)(0-4) 133$ & $0.4(0.69)(0-4)$ & 124 & $0.4(0.73)(0-4)$ & 112 & $-50 \%$ & $\begin{aligned} * & <0.001 \\
& * *<0.001\end{aligned}$ & $<0.001$ \\
\hline $\begin{array}{l}\text { Presence of early } \\
\text { morning dysto- } \\
\text { nia (Item 35) }\end{array}$ & $58(44 \%)(0-1) 133$ & $35(28 \%)$ & 127 & $28(25 \%)$ & 113 & $-43 \%$ & $\begin{array}{l}* 0.002 \\
\quad * *<0.001\end{array}$ & $\begin{array}{c}<0.001 \\
\quad(\text { Logit) }\end{array}$ \\
\hline $\begin{array}{l}\text { OFF time dura- } \\
\text { tion (Item 39) }\end{array}$ & $2.0(0.81)(0-4) 137$ & $0.9(0.69)(0-3)$ & 127 & $1.0(0.75)(0-3)$ & 114 & $-50 \%$ & $\begin{array}{l}*<0.001 \\
\quad * *<0.001\end{array}$ & $<0.001$ \\
\hline \multicolumn{9}{|c|}{ UPDRS I total score } \\
\hline OFF & $6.8(4.75)(0-16) 79$ & $5.9(3.86)(0-16)$ & 81 & $6.0(3.71)(1-16)$ & 65 & $-12 \%$ & $* 0.054$ & 0.006 \\
\hline $\mathrm{ON}$ & $4.3(3.08)(0-12) 96$ & $3.6(2.71)(0-12)$ & 126 & $3.8(2.78)(0-12)$ & 110 & $-12 \%$ & $* * 0.055$ & 0.008 \\
\hline \multicolumn{9}{|l|}{$\begin{array}{l}\text { UPDRS II (ADL) } \\
\text { total score }\end{array}$} \\
\hline OFF & $29.2(9.63)(0-48) 97$ & $\begin{array}{l}25.7(8.49) \\
\quad(8-43)\end{array}$ & 86 & $\begin{array}{l}25.5(8.76) \\
(8-46)\end{array}$ & 72 & $-13 \%$ & $\begin{aligned} * & <0.001 \\
& * * 0.003\end{aligned}$ & $<0.001$ \\
\hline ON & 18.2 (9.39) (0-39) 111 & $\begin{array}{c}16.2(8.49) \\
(1-43)\end{array}$ & 127 & $\begin{array}{c}16.2(8.45) \\
(1-34)\end{array}$ & 109 & $-11 \%$ & $* 0.003 * * 0.078$ & $<0.001$ \\
\hline \multicolumn{9}{|c|}{ UPDRS V (Hoehn and Yahr) } \\
\hline OFF & $3.99(0.82)(2-5) 120$ & $\begin{array}{l}3.59(0.85) \\
(1-5)\end{array}$ & 100 & $3.7(0.81)(2-5)$ & 88 & $-7 \%$ & $\begin{array}{l}*<0.001 \\
* * 0.003\end{array}$ & $<0.001$ \\
\hline ON & $3.07(0.75)(1-5) 135$ & $2.72(0.77)(0-5)$ & 128 & $2.77(0.83)(0-5)$ & 115 & $-10 \%$ & $\begin{aligned} * & <0.001 \\
& * *<0.001\end{aligned}$ & $<0.001$ \\
\hline
\end{tabular}

$A D L$ activities of daily living, $B L$ baseline, $L C I G$ levodopa/carbidopa intestinal gel, $S D$ standard deviation; UPDRS, United Parkinson's Disease Rating Scale

Significant improvement in PDSS-2, GFQ and QUIPRS was also observed across all study visits. Among the QUIP-RS sub-items, sexual behavior, eating, and medication use showed a significant improvement compared to baseline only in the prospective population. The RSS for caregiver burden assessment did not show significant changes during the study compared to BL. The corresponding ANOVA analysis for repeated measurement confirmed these results except for GFQ and QUIP-Medication use (Table 4).

Moreover, the clinicians considered $96 \%$ of the patients as "improved" since the first visit while only in $4 \%$ of the cases they reported a clinical worsening. Similarly, the patients' judgment on their QoL was "very good" or "satisfactory" in $91 \%$ of the cases at the last visit with a positive trend across the study (Fig. 4).

\section{Secondary efficacy analysis}

The sub-analyses according to age, disease duration, and time since infusion $(<1$ year $v s \geq 1$ year) showed that, compared to BL, there was a significant improvement at V2 and V3 of the UPDRS II score during "ON" (respectively, $p=0.001$ and $p=0.006$ ) and at V3 of the UPDRS IV total score $(p=0.02)$ in patients with shorter ( $\leq 13$ years) compared with those with longer PD duration ( $>13$ years). A significant improvement was observed at V2 of the UPDRS-I in OFF $(p=0.043)$ in patients aged $\leq 70$ years; on the contrary, the same patients showed a significant worsening at V3 in UPDRS-IV total score $(p=0.024)$, UPDRS-IV item $32(p=0.02)$, and UPDRS-IV item 33 ( $p=0.011)$ compared with those being more than 70 years old, as reported in Table 5. Moreover, comparison based on the time since infusion, both at V2 and at V3, did 
Table 4 Outcome of non-motor symptoms and PD-associated symptoms at baseline and after LCIG at each treatment visit

\begin{tabular}{|c|c|c|c|c|c|}
\hline Prospective population without LOCF & $\begin{array}{l}\text { Baseline/V1 } \\
\text { Mean } \pm \text { SD }\end{array}$ & Visit 2 Mean \pm SD & Visit 3 Mean \pm SD & $p$ vs baseline & $\begin{array}{l}p \text { ANOVA for } \\
\text { repeated meas- } \\
\text { ures }\end{array}$ \\
\hline PDQ-39 (score 0-156) & $72.3 \pm 23.8$ & $64.7 \pm 25.4^{*}$ & $67.3 \pm 26.4^{* *}$ & $* p<0.001 * * \mathrm{p}<0.05$ & $<.0 .001$ \\
\hline PDSS-2 (score 0-60) & $25 \pm 10.4$ & $22.5 \pm 9.9 *$ & $22.7 \pm 10.1$ & $* p<0.01$ & 0.016 \\
\hline GFQ (score 0-64) & $29.7 \pm 13.3$ & $26.5 \pm 13.1^{*}$ & $26.1 \pm 12$ & $* p<0.05$ & 0.079 \\
\hline QUIP-RS (score 0-112) & $10.4 \pm 16.6$ & $7.8 \pm 13^{*}$ & $7.1 \pm 10.1^{*}$ & $* p<0.05$ & 0.011 \\
\hline QUIP-gambling (score 0-16) & $1.2 \pm 3.3$ & $0.9 \pm 2.6$ & $0.5 \pm 1.7$ & NS & 0.085 \\
\hline QUIP-sexual behavior & $1.5 \pm 2.8$ & $1.1 \pm 2.5^{*}$ & $1.2 \pm 2.7$ & $* p<0.05$ & 0.140 \\
\hline QUIP-buying & $1.5 \pm 3.2$ & $1.1 \pm 2.3$ & $0.8 \pm 1.8$ & NS & 0.100 \\
\hline QUIP-eating & $2.2 \pm 4$ & $1.8 \pm 3.6$ & $1.5 \pm 3 *$ & $* p<0.05$ & 0.051 \\
\hline QUIP-hobbism & $1.3 \pm 2.7$ & $1.2 \pm 26$ & $1.3 \pm 2.5$ & NS & 0.815 \\
\hline QUIP-punding & $1.3 \pm 3.4$ & $1 \pm 2.6$ & $0.7 \pm 1.9$ & NS & 0.128 \\
\hline QUIP-Medication use & $1.4 \pm 3.5$ & $0.7 \pm 2.1 *$ & $1.2 \pm 3$ & $* p<0.01$ & 0.093 \\
\hline RSS-2 (score 15-75) & $40.2 \pm 12.4$ & $39 \pm 13.3$ & $38.3 \pm 13$ & NS & 0.237 \\
\hline RSS/personal distress & $16.5 \pm 5.5$ & $16.1 \pm 5.7$ & $15.9 \pm 5.6$ & NS & 0.467 \\
\hline RSS/negative feeling & $9.2 \pm 3.6$ & $8.9 \pm 3.7$ & $8.7 \pm 3.5$ & NS & 0.085 \\
\hline RSS/life upset & $14.5 \pm 5$ & $14 \pm 5.1$ & $13.7 \pm 5$ & NS & 0.455 \\
\hline
\end{tabular}

ADL, activities of daily living; BL, baseline; LCIG; levodopa/carbidopa intestinal gel; SD, standard deviation; UPDRS, United Parkinson's Disease Rating Scale

${ }^{*} p$ value at $\mathrm{V} 2$ vs $\mathrm{BL},{ }^{* *} p$ value at $\mathrm{V} 3$ vs $\mathrm{BL}$

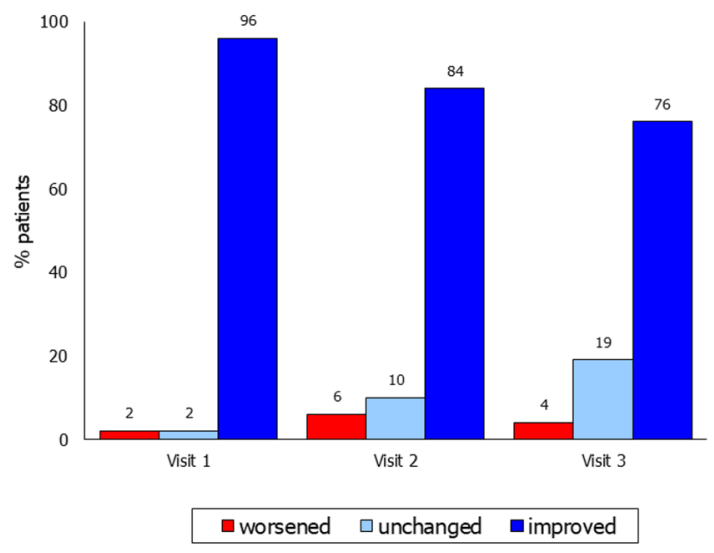

a Neurologist's clinical judgement rated by a 3-point scale

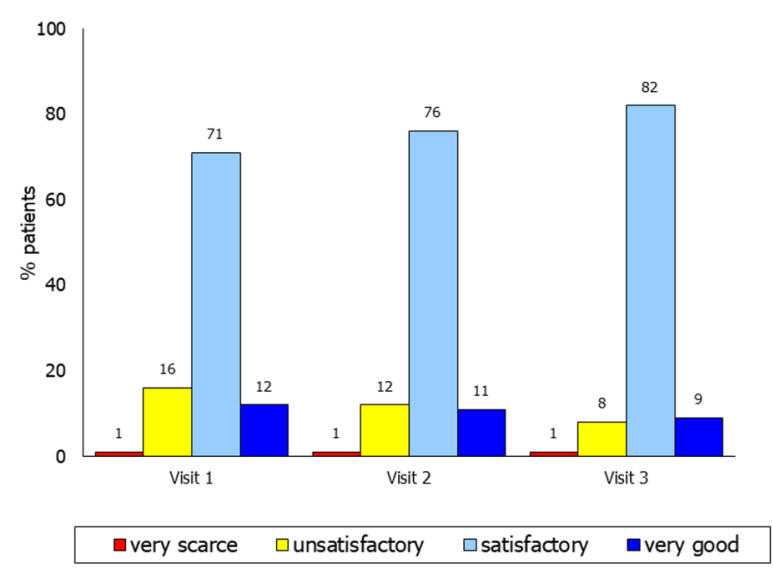

b Score varied between 0 (very scarce) to 10 (very good) and grouped for the analysis as 0-2: very scarce, 3-5 unsatisfactory, 6-8 satisfactory, 9-10 very good
Fig. 4 Global efficacy of LCIG made by neurologists vs baseline (a) and patient 's judgement on LCIG therapy at each visit (b). a Neurologist's clinical judgement rated by a three-point scale. b Score var- ied between 0 (very scarce) and 10 (very good) and grouped for the analysis as $0-2$ very scarce, $3-5$ unsatisfactory, 6-8 satisfactory, 9-10 very good

\section{Adverse events} except for a significant improvement in UPDRS-I ON $(p=0.036$ and $p=0.004)$ and in UPDRS-II ON $(p=0.012$ and $p=0.019)$, and in UPDRS-IV item $33(p=0.012$ at V2) in patients with less than 1 year of LCIG infusion (Table 5).
Overall, 40 (27.6\%) patients experienced one or more SAEs (Table 6). The most frequently reported SAE, among those reported with a frequency higher than $1 \%$, during LCIG infusion period were pneumonia (2.8\%), femur fracture and cardiac failure $(2.1 \%)$, peripheral neuropathy $(1.4 \%)$, worsening of $\mathrm{PD}$, fasciitis, and peritonitis (1.4\% each). Only 8 out 
Table 5 Impact of age of the patient, duration of disease and of time since infusion on the UPDRS scores ANCOVA model

\begin{tabular}{|c|c|c|c|c|c|c|}
\hline \multirow[t]{2}{*}{ All population-ANCOVA model } & \multicolumn{3}{|c|}{ Visit 2-year 1} & \multicolumn{3}{|c|}{ Visit 3-year 2} \\
\hline & Mean change & $\begin{array}{l}95 \% \text { confidence } \\
\text { Interval }\end{array}$ & $p$ value & $\begin{array}{l}\text { Mean } \\
\text { change }\end{array}$ & $\begin{array}{l}95 \% \text { confidence } \\
\text { interval }\end{array}$ & $p$ value \\
\hline \multicolumn{7}{|l|}{ UPDRS item 39} \\
\hline Age $(<=70$ vs $>70$ years $)$ & 0.01 & -0.27 to 0.265 & 0.947 & 0.16 & -0.11 to 0.43 & 0.242 \\
\hline Time since $\mathrm{PD}$ diagnosis ( $<=13$ vs $>13$ years $)$ & -0.15 & -0.41 to 0.10 & 0.245 & -0.20 & -0.47 to 0.07 & 0.142 \\
\hline Baseline & & & 0.798 & & & 0.153 \\
\hline Time since infusion (prospective vs retrospective) & 0.05 & -0.21 to 0.31 & 0.694 & 0.14 & -0.13 to 0.40 & 0.302 \\
\hline \multicolumn{7}{|l|}{ UPDRS I ‘ON’ } \\
\hline Age $(<=70$ vs $>70$ years $)$ & 0.37 & -0.64 to 1.38 & 0.473 & 0.32 & -0.82 to 1.456 & 0.576 \\
\hline Time since $\mathrm{PD}$ diagnosis ( $<=13$ vs $>13$ years $)$ & -0.73 & -1.72 to 0.27 & 0.151 & -0.27 & -1.39 to 0.85 & 0.633 \\
\hline Baseline & & & 0.001 & & & 0.046 \\
\hline Time since infusion (prospective vs retrospective) & -1.12 & -2.16 to $-\mathbf{0 . 0 7}$ & 0.036 & -1.72 & -2.88 to $-\mathbf{0 . 5 6}$ & 0.004 \\
\hline \multicolumn{7}{|l|}{ UPDRS I 'OFF' } \\
\hline Age $(<=70$ vs $>70$ years $)$ & -1.47 & $-\mathbf{2 . 8 9}$ to $-\mathbf{0 . 0 5}$ & 0.043 & -1.24 & -3.29 to 0.81 & 0.231 \\
\hline Time since PD diagnosis ( $<=13$ vs $>13$ years) & 0.91 & -0.42 to 2.4125 & 0.177 & -0.04 & -1.91 to 1.84 & 0.967 \\
\hline Baseline & & & $<0.001$ & & & $<0.001$ \\
\hline Time since infusion (prospective vs retrospective) & -1.16 & -2.47 to 0.15 & 0.081 & -1.20 & -3.01 to 0.60 & 0.187 \\
\hline \multicolumn{7}{|l|}{ UPDRS II 'ON' } \\
\hline Age $(<=70$ vs $>70$ years $)$ & 1.10 & -1.59 to 3.78 & 0.420 & 1.23 & -1.65 to 4.11 & 0.399 \\
\hline Time since $\mathrm{PD}$ diagnosis $(<=13$ vs $>13$ years $)$ & -4.59 & -7.30 to $-\mathbf{1 . 8 8}$ & 0.001 & -4.09 & -6.99 to -1.19 & 0.006 \\
\hline Baseline & & & $<0.001$ & & & $<0.001$ \\
\hline Time since infusion (prospective vs retrospective) & $-\mathbf{3 . 5 2}$ & -6.25 to $-\mathbf{0 . 7 8}$ & 0.012 & $-\mathbf{3 . 5 3}$ & -6.46 to $-\mathbf{0 . 5 9}$ & 0.019 \\
\hline \multicolumn{7}{|l|}{ UPDRS II 'OFF' } \\
\hline Age $(<=70$ vs $>70$ years $)$ & -2.95 & -6.29 to 0.39 & 0.083 & -1.53 & -5.11 to 2.04 & 0.396 \\
\hline Time since $\mathrm{PD}$ diagnosis $(<=13$ vs $>13$ years $)$ & -2.25 & -5.52 to 1.02 & 0.175 & -3.08 & -6.59 to 0.42 & 0.084 \\
\hline Baseline & & & $<0.001$ & & & $<0.001$ \\
\hline Time since infusion (prospective vs retrospective) & -2.44 & -5.79 to 0.92 & 0.152 & -1.95 & -5.54 to 1.65 & 0.284 \\
\hline \multicolumn{7}{|l|}{ UPDRS IV (A + B) } \\
\hline Age $(<=70$ vs $>70$ years $)$ & 0.32 & -0.72 to 1.36 & 0.545 & 1.18 & 0.16 to 2.21 & 0.024 \\
\hline Time since $\mathrm{PD}$ diagnosis $(<=13$ vs $>13$ years $)$ & -0.89 & -1.93 to 0.15 & 0.094 & -1.22 & -2.24 to $-\mathbf{0 . 1 9}$ & 0.020 \\
\hline Baseline & & & 0.005 & & & $<0.001$ \\
\hline Time since infusion (prospective vs retrospective) & -0.63 & -1.68 to 0.42 & 0.236 & -0.60 & -1.62 to 0.43 & 0.254 \\
\hline \multicolumn{7}{|l|}{ UPDRS Dyskinesia score: ITEM 32} \\
\hline Age $(<=70$ vs $>70$ years $)$ & 0.19 & -0.13 to 0.50 & 0.246 & 0.41 & 0.06 to 0.76 & $\mathbf{0 . 0 2 0}$ \\
\hline Time since $\mathrm{PD}$ diagnosis $(<=13$ vs $>13$ years $)$ & -0.13 & -0.45 to 0.18 & 0.591 & -0.23 & -0.58 to 0.11 & 0.186 \\
\hline Baseline & & & 0.001 & & & 0.015 \\
\hline Time since infusion (prospective vs retrospective) & -0.09 & -0.41 to 0.23 & 0.591 & 0.02 & -0.32 to 0.37 & 0.895 \\
\hline \multicolumn{7}{|l|}{ UPDRS Dyskinesia score: ITEM 33} \\
\hline Age $(<=70$ vs $>70$ years $)$ & 0.12 & -0.25 to 0.49 & 0.527 & 0.45 & $\mathbf{0 . 1 1}$ to $\mathbf{0 . 8 0}$ & 0.011 \\
\hline Time since $\mathrm{PD}$ diagnosis $(<=13$ vs $>13$ years $)$ & -0.11 & -0.49 to 0.26 & 0.544 & -0.14 & -0.48 to 0.21 & 0.443 \\
\hline Baseline & & & 0.050 & & & 0.081 \\
\hline Time since infusion (prospective vs retrospective) & -0.48 & -0.85 to -0.11 & 0.012 & -0.4 & -0.69 to 0.01 & 0.055 \\
\hline \multicolumn{7}{|l|}{ UPDRS Dyskinesia score: ITEM 34} \\
\hline Age $(<=70$ vs $>70$ years $)$ & 0.021 & -0.22 to 0.25 & 0.899 & 0.06 & -0.19 to 0.30 & 0.658 \\
\hline Time since $\mathrm{PD}$ diagnosis $(<=13$ vs $>13$ years $)$ & 0.06 & -0.18 to 0.29 & 0.636 & -0.13 & -0.38 to 0.12 & 0.300 \\
\hline Baseline & & & $<0.001$ & & & $<0.001$ \\
\hline Time since infusion (prospective vs retrospective) & -0.14 & -0.38 to 0.09 & 0.232 & 0.02 & -0.23 to 0.27 & 0.873 \\
\hline
\end{tabular}

Variables in bold are statistical significant for at least $p<0.05$ 
Table 6 Overall safety in the retrospective and prospective data collection cohorts

\begin{tabular}{|c|c|}
\hline N. of patients with SAEs & $40(27.6 \%)$ \\
\hline Event by preferred term & N. Events \\
\hline Pneumonia & $4(2.8 \%)$ \\
\hline Femur fracture & $3(2.1 \%)$ \\
\hline Cardiac failure & $3(2.1 \%)$ \\
\hline Cardiac arrest & $2(1.4 \%)$ \\
\hline Peripheral neuropathy & $2(1.4 \%)$ \\
\hline Worsening of PD & $2(1.4 \%)$ \\
\hline Peritonitis & $2(1.4 \%)$ \\
\hline Death & $2(1.4 \%)$ \\
\hline Fasciitis & $2(1.4 \%)$ \\
\hline Hip fracture & $1(0.7 \%)$ \\
\hline Humerus fracture & $1(0.7 \%)$ \\
\hline Cerebral haematoma & $1(0.7 \%)$ \\
\hline Headache & $1(0.7 \%)$ \\
\hline Hyperkinesia & $1(0.7 \%)$ \\
\hline Acute myocardial infarction & $1(0.7 \%)$ \\
\hline Gastric ulcer & $1(0.7 \%)$ \\
\hline Haematemesis & $1(0.7 \%)$ \\
\hline Inguinal hernia & $1(0.7 \%)$ \\
\hline Intestinal obstruction & $1(0.7 \%)$ \\
\hline Agitation & $1(0.7 \%)$ \\
\hline Visual hallucination & $1(0.7 \%)$ \\
\hline Suicide attempt & $1(0.7 \%)$ \\
\hline Abnormal weight loss & $1(0.7 \%)$ \\
\hline Hypoglycemia & $1(0.7 \%)$ \\
\hline Acute pulmonary oedema & $1(0.7 \%)$ \\
\hline Pulmonary embolism & $1(0.7 \%)$ \\
\hline Anemia & $1(0.7 \%)$ \\
\hline Deep vein thrombosis & $1(0.7 \%)$ \\
\hline \multicolumn{2}{|l|}{ Related to PEG/J procedure or to device } \\
\hline Wrong technique in drug usage process & $2(1.4 \%)$ \\
\hline Gastrostomy tube site complication & $1(0.7 \%)$ \\
\hline Pyrexia & $1(0.7 \%)$ \\
\hline Administration site infection & $1(0.7 \%)$ \\
\hline Stoma site infection & $1(0.7 \%)$ \\
\hline Device occlusion & $1(0.7 \%)$ \\
\hline Medical device complication & $1(0.7 \%)$ \\
\hline Total SAEs & 49 \\
\hline AEs leading to discontinuation & N. patients \\
\hline Any $\mathrm{AE}$ leading to discontinuation & $12(8.3 \%)$ \\
\hline Device occlusion/device complication & $2(1.4 \%)$ \\
\hline Abnormal weight loss/hypoglycemia & $2(1.4 \%)$ \\
\hline Fasciitis & $2(1.4 \%)$ \\
\hline Peripheral sensory neuropathy & $2(1.4 \%)$ \\
\hline Cardiac arrest & $1(0.7 \%)$ \\
\hline Peritonitis & $1(0.7 \%)$ \\
\hline Hallucination, visual & $1(0.7 \%)$ \\
\hline Acute pulmonary oedema & $1(0.7 \%)$ \\
\hline
\end{tabular}

Table 6 (continued)

\begin{tabular}{ll}
\hline N. of patients with SAEs & $40(27.6 \%)$ \\
\hline Product quality complaints during the study & \\
PQC experienced & $54(37.2 \%)$ \\
Event by preferred term & N. Events \\
Complaints associated with an adverse events & $43(29.7 \%)$ \\
Complaints associated with an ADR & $29(20 \%)$ \\
Complaints associated with a SAE & $14(9.7 \%)$ \\
Risks of PEG insertion & $4(2.8 \%)$ \\
Immediate peristomal infections & 2 \\
Bleedings and injury of internal organs & 1 \\
Infections including peritonitis and pneumoperitoneum & 1 \\
Device Complications (Infusion system) & $30(20.7 \%)$ \\
Accidental removal of PEG tube & 2 \\
Tube occlusion & 11 \\
Dislocation of duodenal tube & 7 \\
Tube rupture, accidental removal, device leakage & 5 \\
Phytobezoar & 5 \\
Surgical procedure & $13(9 \%)$ \\
Encrusted dressing & 1 \\
Signs of inflammation & 3 \\
Granulation tissue & 9 \\
Pump complication/rupture & $8(5.5 \%)$ \\
\hline
\end{tabular}

of 49 SAEs (16.3\%) were related to PEG/J procedure or to device. (Table 6). In 12 out of 145 patients (8.3\%) the AEs lead to discontinuation, as reported in Table 6. Fifty-four patients (37.2\%) experienced PQCs; the most frequent were tube occlusion in 11 cases, dislocation of duodenal tube in 7 cases and phytobezoar in 5 cases (Table 6).

Thirteen deaths (9\%) occurred during the observational period, mainly for cardiac reasons (six cases). For 12 deaths, a reasonably possible relationship has been reported.

\section{Discussion}

Here, we report the final results from the largest cohort of patients with APD treated with LCIG in routine clinical practice from 14 Italian Movement Disorder Centers. The APD patients in this study were affected by motor fluctuations and dyskinesia not optimally controlled by standard oral or transdermal therapies. The previously published interim analysis of this study showed a significant reduction in total daily OFF time after a mean of 1.4 years of LCIG therapy with a magnitude of improvement consistent with the results reported in previous studies [22].

Results from this final analysis of up to 8 years of LCIG treatment (with a mean duration of 3 years) showed significant improvements on motor fluctuations, ADL and QoL. The magnitude of OFF reduction observed in our study is 
in agreement with the recently published data, where OFF reductions varied from 48 to $67 \%$ [8, 12, 20, 21, 23-25].

Moreover, the high percentage of patients reporting a UPDRS-IV item-39 score between 0 and 1 during LCIG infusion (approximately $80 \%$ at each visit) is also in line with the recently reported data from the PREDICT crosssectional study where the percentage for this score was $81 \%$ for patients treated with LCIG and only $17 \%$ in patients treated with oral standard PD therapies [26]. The clinical relevance of this finding is further supported by the significant improvement of all UPDRS IV items related to dyskinesia and the total score of UPDRS IV.

The results of previous clinical studies on LCIG infusion have already indicated that this is an effective therapeutic strategy for improvements of motor symptoms (reduction in OFF time, increase in ON time without disabling dyskinesia, reduction of troublesome dyskinesia) [17, 27], non-motor symptoms (somnolence, fatigue, cardiovascular and urinary function, tremor at rest), and QoL [10, 28-30].

We observed significant improvements in UPDRS II for ADL, comparable to those reported in a 12-month prospective observational study including APD patients treated with LCIG as they start presenting with motor complications, having either 2-4 h of OFF time or $2 \mathrm{~h}$ of dyskinesia daily. In this study, patients experienced significant improvements from baseline in non-motor symptoms, with corresponding improvements in ADL up to 12 months [13].

Significant improvements compared to baseline were observed in the prospective population for QoL assessed by PDQ-39, quality of sleep assessed by PDSS-2, gait and balance disorders assessed by GFQ, and compulsive behavior by QUIP-RS with a significant impact on sexual behavior, eating, and medication use habit. A significant efficacy on these non-motor complications was previously also reported by Fasano et al. in a small group of patients treated with LCIG for 24 months [31]. Our results on sleep are in line with previously published data showing that LCIG improved the quality of sleep and produced a less fragmented sleep pattern measured by polysomnography after 6 months of therapy $[32,33]$.

It is interesting to note that in addition to the already established efficacy on motor and non-motor symptoms, there are clinically meaningful data regarding the positive effect of LCIG on axial symptoms. In fact, it has recently been reported in a retrospective study on 32 advanced PD patients, that LCIG has a favorable effect on freezing of gait (FoG), mainly represented by Pseudo-ON FoG and OFFtype-FoG [25, 34]. Moreover, LCIG was shown to be effective in seven PD patients with prominent episodes of freezing refractory to oral therapy [35].

In the sub-analyses of this study, we observed that patients with a shorter PD duration ( $\leq 13$ years) had a better outcome on motor complications and ADL compared to patients with a longer PD duration, while the age is discriminant only for motor complications which are slightly more disabling in younger compared to older patients.

The finding that patients with shorter disease duration had a greater efficacy in ADL is in line with the results obtained in the MONOTREAT study, where ADL score was significantly improved starting from 3 months of treatment in patients with 13 years of PD duration and with short daily OFF time period (2-4 h) or dyskinesia period ( $2 \mathrm{~h}$ of troublesome or non-troublesome dyskinesia) [13].

These evidences strongly suggest that, in advanced PD patients, early treatment with LCIG should be carefully and promptly evaluated to improve motor complications and daily living activities.

The safety results were consistent with the established profile of LCIG [30, 21, 36, 37]. The percentage of SAEs was in the range of the adverse drug reactions reported in the complete GLORIA observational registry [24], with device and procedure-related events more frequently reported. These observations must be taken into consideration on the necessity for close monitoring in the immediate post PEG/J positioning period and in the long-term follow-up.

This is the first Italian study with data from a large population followed for a long period of time. Since this investigation was observational, with the collection of data recorded during routine medical care, we consider these outcomes to be close to "real-world' clinical practice and consistent with results generated in controlled short-term clinical studies. The mean treatment period in this cohort was approximately 3 years; clinical outcomes were followed through 24 months of follow-up in this cohort of 145 patients with APD to assess the benefits of LCIG infusion therapy for up to 8 years of treatment.

\section{Limitations and strengths}

Due to the partly retrospective design, many questionnaires and scales included in the protocol were not available at baseline especially in patients already in treatment with LCIG for more than 1 year. Therefore, the questionnaires with baseline assessment were available only in the smaller sample represented by the prospective population.

Since this was an observational study with the use of LCIG in routine care, the outcomes may be considered to be close to the real-world clinical practice, even if in the absence of a true control group.

Further limitation of this study is the fact that the results are not corrected for the levodopa equivalent daily dose of concomitant oral/transdermal antiparkinsonian medications. Although the use of concomitant medications was reduced after LCIG start, patients were still taking some antiparkinsonian or antidyskinetic during the study; therefore, 
improvements in dyskinesias and fluctuations may be also due an adjunctive effect.

The sub-analyses took into account the age of patients at the enrollment and not the age at LCIG implant, considering that age at treatment initiation is another important aspect in LCIG selection criteria. This would have allowed a comparison with the results obtained in an interesting prospective, open-label study in 28 patients with APD treated with LCIG for a mean treatment period of 24 months. In that study, younger age at operation and absence or presence of mild psychiatric/behavioral symptoms were positive predictive factors in selecting the best candidates for LCIG therapy [23].

\section{Conclusion}

In conclusion, these results confirm that treatment with LCIG in the long term produces clinically significant improvements on motor function, non-motor symptoms, including sleep and impulsive disorders, and ADL in PD patients not optimally controlled by oral/transdermal therapies. This study also suggested a greater improvement in motor fluctuation and in ADL in advanced PD patients treated earlier since PD onset. Adverse effects and complications have been observed during the study period; therefore, the proper indications for LCIG should be always taken into account for the selection of a patient, considering the benefit against safety issues.

Acknowledgements The authors wish to acknowledge the other investigators from Italy who participated in this study in the collection of data: Deborah Lanni (Pozzilli IS), Brigida Minafra (Pavia), Pamela Pastorello (Biella), Alfonso Rubino (Roma), Rossella Scatozza (Roma), Maria Rosaria Seminara (Catania), Annarita Sorrentino (Mestre VE), and Francesco Bove, Maria Gabriella Vita, and Maria Elena Riccioni (Fodazione Policlinico Universitario A. Gemelli IRCCS).

Funding This work was funded by AbbVie Srl. AbbVie participated in the study design, research, data collection, analysis and interpretation of data, and writing, reviewing, and approving the publication.

\section{Compliance with ethical standards}

Conflicts of interest Angelo Antonini has received compensation for consultancy and speaker-related activities from UCB, Boehringer Ingelheim, AbbVie, Zambon, Bial, Lundbeck; he receives research support from Chiesi Pharmaceuticals, Lundbeck, Horizon 2020 - PD_Pal Grant 825785, Ministry of Education University and Research (MIUR) Grant ARS01_01081. He serves as consultant for Boehringer-Ingelheim for legal cases on pathological gambling. Graziano Gusmaroli, Pietro Marano, Nicola Modugno, Rocco Quatrale, Mariachiara Sensi, Paolo Solla, and Filippo Tamma have received honoraria for consulting services and symposia from AbbVie. Leonardo Lopiano has received honoraria for consulting services and symposia from AbbVie, Zambon, UCB, DOC, Chiesi, and Bial. Francesca Mancini has received honoraria for consulting services and symposia from AbbVie and Zambon. Roberto Eleopra has received compensation for consultancy and speaker-related activities from Ipsen SpA, Boston Scientific, BrainLab Germany. Rocco Quatrale has received compensation for consultancy and speaker from AbbVie and Zambon. Annarita Bentivoglio received honorarium for participation in advisory board from Merz and AbbVie and has received compensation for speaker-related activities from AbbVie, UCB, Lundbeck, Bial, Neuroderm, Zambon, Allergan, Ipsen. Roberta Zangaglia has received honoraria for speakerrelated activities from AbbVie and Boston Scientific. Giuseppe Meco has nothing to disclose. Giuliana Gualberti and Gabriella Melzi are employees of AbbVie Italy and may own AbbVie stocks/options.

Ethical approval The protocol of the study was approved by the Ethics Committee of each local health authority and each patient provided informed consent. The study was conducted in accordance with the principles of the International Conference on Harmonization Good Clinical Practices.

Open Access This article is distributed under the terms of the Creative Commons Attribution 4.0 International License (http://creativeco mmons.org/licenses/by/4.0/), which permits unrestricted use, distribution, and reproduction in any medium, provided you give appropriate credit to the original author(s) and the source, provide a link to the Creative Commons license, and indicate if changes were made.

\section{References}

1. Martinez-Martin P, Rodriguez-Blazquez C, Forjaz MJ (2012) Quality of life and burden in caregivers for patients with Parkinson's disease: concepts, assessment and related factors. Expert Rev Pharmacoecon Outcomes Res 12(2):221-230

2. Freitas EM, Hess CW, Fox SH (2017) Motor complications of dopaminergic medications in Parkinson's disease. Semin neurol 37(2):147-157

3. Altavista MC, Cassetta E, Brusa L, Viselli F, Denaro A, Ventriglia M, Pasqualetti P, Peppe A (2015) Wearing-off detection in clinical practice: the wearing off real practice key (WORK-PD) study in parkinson's disease. Parkins Rel Disord 21:95-100

4. Antonini A, Moro E, Godeiro C, Reichmann H (2018) Medical and surgical management of advanced Parkinson's disease. Mov Disord 33(6):900-908.

5. Nyholm D, Odin P, Johansson A, Chatamra K, Locke C, Dutta S, Othman AA (2013) Pharmacokinetics of levodopa, carbidopa, and 3-O-methyldopa following 16-hour jejunal infusion of levodopacarbidopa intestinal gel in advanced Parkinson's disease patients. AAPS J 15:316-323

6. Antonini A, Nitu B (2018) Apomorphine and levodopa infusion for motor fluctuations and dyskinesia in advanced Parkinson disease. J Neural Transm 125(8):1131-1135. https://doi.org/10.1007/ s00702-018-1906-0

7. Wirefeldt K, Odin P, Nyholm D (2016) Levodopa-carbidopa intestinal gel in patients with Parkinson's disease: a systematic review. CNS Drugs 30:381-404

8. Olanow CW, Kieburtz K, Odin P, Espay AJ, Standaert DG, Fernandez $\mathrm{HH}$, Vanagunas A, Othman AA, Widnell KL, Robieson WZ, Pritchett Y, Chatamra K, Benesh J, Lenz RA, Antonini A, for the LCIG Horizon Study Group (2014) Continuous intrajejunal infusion of levodopa-carbidopa intestinal gel for patients with advanced Parkinson's disease: a randomised, controlled, doubleblind, double-dummy study. Lancet Neurol 13(2):141-149

9. Fernandez HH, Standaert DG, Hauser RA, Lang AE, Fung VS, Klostermann F, Lew MF, Odin P, Steiger M, Yakupov EZ, 
Chouinard S, Suchowersky O, Dubow J, Hall CM, Chatamra K, Robieson WZ, Benesh JA, Espay AJ (2015) Levodopa-carbidopa intestinal gel in advanced Parkinson's disease: final 12-month, open-label results. Mov Disord 30(4):500-509

10. Slevin JT, Fernandez HH, Zadikoff C, Hall C, Eaton S, Dubow J, Chatamra K, Benesh J (2015) Long-term safety and maintenance of efficacy of Levodopa-Carbidopa intestinal gel: an open-label extension of the double-blind pivotal study in advanced Parkinson's disease patients. J Parkinsons Dis 5(1):165-174

11. Antonini A, Fung VSC, Boyd JT, Slevin JT, Hall C, Chatamra K, Eaton S, Benesh JA (2016) Effect of levodopa-carbidopa intestinal gel on dyskinesia in advanced Parkinson's disease patients. Mov Disord 31(4):530-537. https://doi.org/10.1002/mds.26528

12. Timpka JF, Fox T, Fox K, Honig H, Odin P, Martinez-Martin P, Antonini A, Chauduri RK (2016) Improvement of dyskinesias with 1-dopa infusion in advanced Parkinson's disease. Acta Neurol Scand 133(6):451-458. https://doi.org/10.1111/ane.12483

13. Kruger R, Lingor P, Doskas T, Henselmans JML, Danielsen EH, de Fabregues O, Stefani A, Sensken SC, Parra JC, Onuk K, Yegin A, Antonini A (2017) An observational study of the effect of levodopacarbidopa intestinal gel on activities of daily living and quality of life in advanced Parkinson's disease patients. Adv Ther 34(7):17411752. https://doi.org/10.1007/s12325-017-0571-2

14. Antonini A, Yegin A, Preda C, Bergmann L, Poewe W, GLORIA study investigators, and coordinators (2015) Global long-term study on motor and non-motor symptoms and safety of levodopa-carbidopa intestinal gel in routine care of advanced Parkinson's disease patients; 12-month interim outcomes. Parkins Rel Disord 21(3):231235. https://doi.org/10.1016/j.parkreldis.2014.12.012

15. Buongiorno M, Antonelli F, Cámara A, Puente V, de FabreguesNebot O, Hernandez-Vara J, Calopa M, Pascual-Sedano B, Campolongo A, Valldeoriola F, Tolosa E, Kulisevsky J, Martí MJ (2015) Long-term response to continuous duodenal infusion of levodopa/ carbidopa gel in patients with advanced Parkinson disease: the Barcelona registry. Parkins Rel Disord 21(8):871-876. https://doi. org/10.1016/j.parkreldis.2015.05.014

16. Pickut BA, van der Linden C, Dethy S, Van De Maele H, de Beyl DZ (2014) Intestinal levodopa infusion: the Belgian experience. Neurol Sci 35(6):861-866. https://doi.org/10.1007/s10072-013-1612-5

17. Antonini A, Odin P, Lopiano L, Tomantschger V, Pacchetti C, Pickut B, Gasser UE, Calandrella D, Mancini F, Zibetti M, Minafra B, Bertaina I, De Deyn P, Cras C, Wolf E, Spielberger S, Poewe W (2013) Effect and safety of duodenal levodopa infusion in advanced Parkinson's disease: a retrospective multicenter outcome assessment in patient routine care. J Neural Transm 120(11):1553-1558. https ://doi.org/10.1007/s00702-013-1026-9

18. Nyholm D, Klangemo K, Johansson A (2012) Levodopa/carbidopa intestinal gel infusion long-term therapy in advanced Parkinson's disease. Eur J Neurol. 19(8):1079-1085. https://doi.org/10.111 1/j.1468-1331.2012.03679.x

19. Nyholm D, Lewander T, Johansson A, Lewitt PA, Lundqvist C, Aquilonius SM (2008) Enteral levodopa/carbidopa infusion in advanced Parkinson disease: long-term exposure. Clin Neuropharmacol 31(2):63-73. https://doi.org/10.1097/WNF.0b013e3180ed449 $\mathrm{f}$

20. Zibetti M, Merola A, Artusi CA, Rizzi L, Angrisano S, Reggio D, De Angelis C, Rizzone M, Lopiano L (2014) Levodopa/carbidopa intestinal gel infusion in advanced Parkinson's disease: a 7-year experience. Eur J Neurol 21(2):312-318

21. Merola A, Espay AJ, Romagnolo A, Bernardini A, Rizzi L, Rosso M, Espay KJ, Zibetti M, Lanotte M, Lopiano L (2016) Advanced therapies in Parkinson's disease: long-term retrospective study. Parkinsonism Relat Disord. 29:104-108. https://doi.org/10.1016/j.parkr eldis.2016.05.015

22. Lopiano L, Modugno N, Marano P, Sensi M, Meco G, Cannas A, Gusmaroli G, Tamma F, Mancini F, Quatrale R, Costanzo AM,
Gualberti G, Melzi G, di Luzio Paparatti U, Antonini A (2016) Motor outcomes in patients with advanced Parkinson's disease treated with levodopa/carbidopa intestinal gel in Italy: an interim analysis from the GREENFIELD observational study. Neurol Sci. 37(11):1785-1792

23. Sensi M, Preda F, Trevisani L, Contini E, Gragnaniello D, Capone JG, Sette E, Golfrè Andreasi N, Tugnoli V, Tola MR, Quatrale R (2014) Emerging issues on selection criteria of levodopa carbidopa infusion therapy: considerations on outcome of 28 consecutive patients. J Neural Transm 121(6):633-642

24. Antonini A, Poewe W, Chaudhuri KR, Jech R, Pickut B, Pirtošek Z, Szasz J, Valldeoriola F, Winkler C, Bergmann L, Yegin A, Onuk K, Barch D, Odin P, GLORIA study co-investigators (2017) Levodopacarbidopa intestinal gel in advanced Parkinson's: Final results of the GLORIA registry. Parkinsonism Relat Disord. 45:13-20. https://doi. org/10.1016/j.parkreldis.2017.09.018

25. Zibetti M, Angrisano S, Dematteis F, Artusi CA, Romagnolo A, Merola A, Lopiano L (2018) Effects of intestinal Levodopa infusion on freezing of gait in Parkinson disease. J Neurol Sci 385:105-108. https://doi.org/10.1016/j.jns.2017.12.012

26. Tessitore A, Marano P, Modugno N, Pontieri FE, Tambasco N, Canesi M, Latorre A, Lopiano L, Sensi M, Quatrale R, Solla P, Defazio G, Melzi G, Costanzo AM, Gualberti G, di Luzio Paparatti U, Antonini A (2018) Caregiver burden and its related factors in advanced Parkinson's disease: data from the PREDICT study. J Neurol 265(5):1124-1137. https://doi.org/10.1007/s00415-018-8816-9

27. Abbruzzese G, Barone P, Bonuccelli U, Lopiano L, Antonini A (2012) Continuous intestinal infusion of levodopa/carbidopa in advanced Parkinson's disease: efficacy, safety and patient selection. Funct Neurol 27(3):147-154

28. Honig H, Antonini A, Martinez-Martin P, Forgacs I, Faye GC, Fox T, Fox K, Mancini F, Canesi M, Odin P, Chauduri KR (2009) Intrajejunal levodopa infusion in Parkinson's disease. A pilot multicenter study of effects on non motor symptoms and quality of life. Mov Disord 24(10):1468-1474.

29. Reddy P, Martinez-Martin P, Rizos A, Martin A, Faye GC, Forgacs I, Odin P, Antonini A, Chaudhuri KR (2012) Intrajejunal levodopa versus conventional therapy in Parkinson disease: motor and nonmotor effects. Clin Neuropharmacol 35(5):205-217

30. Fernandez HH, Robieson WZ, Chatamra K, Dubow J, Eaton S, Benesh JA, Odin P (2016) Effect of levodopa-carbidopa intestinal gel on resting tremors in patients with advanced Parkinson's disease. NPJ Parkinsons Dis 2:16015. https://doi.org/10.1038/npjpa rkd.2016.15 eCollection 2016

31. Fasano A, Ricciardi L, Lena F, Bentivoglio AR, Modugno N (2012) Intrajejunal levodopa infusion in advanced Parkinson's disease: long-term effects on motor and non-motor symptoms and impact on patient's and caregiver's quality of life. Eur Rev Med Pharmacol Sci. 16(1):79-89

32. Zibetti M, Rizzone M, Merola A, Angrisano S, Rizzi L, Montanaro E, Cicolin A, Lopiano L (2013) Sleep improvement with levodopa/ carbidopa intestinal gel infusion in Parkinson disease. Acta Neurol Scand 127(5):e28-e32. https://doi.org/10.1111/ane.12075

33. Zibetti M, Romagnolo A, Merola A, Priano L, Montanaro E, Angrisano S, Tribolo A, Cicolin A, Lopiano L (2017) A polysomnographic study in parkinsonian patients treated with intestinal levodopa infusion. J Neurol. 264(6):1085-1090. https://doi.org/10.1007/s0041 5-017-8491-2

34. Rispoli V, Golfrè Andreasi N, Penna G, Preda F, Contini E, Sensi M (2018) Levodopa/carbidopa intestinal gel infusion therapy: focus on gait and balance. Mov Disord Clin Pract 25;5(5):542-545. https:// doi.org/10.1002/mdc3.12640

35. Cossu G, Ricchi V, Pilleri M, Mancini F, Murgia D, Ricchieri G, Mereu A, Melis M, Antonini A (2015) Levodopa-carbidopa intrajejunal gel in advanced Parkinson disease with "on" freezing of 
gait. Neurol Sci. 36(9):1683-1686. https://doi.org/10.1007/s1007 2-015-2234-x

36. Lang AE, Rodriguez RL, Boyd JT, Chouinard S, Zadikoff C, Espay AJ, Slevin JT, Fernandez HH, Lew MF, Stein DA, Odin P, Fung VS, Klostermann F, Fasano A, Draganov PV, Schmulewitz N, Robieson WZ, Eaton S, Chatamra K, Benesh JA, Dubow J (2016) Integrated safety of levodopa-carbidopa intestinal gel from prospective clinical trials. Mov Disord. 31(4):538-546. https://doi.org/10.1002/ mds. 26485

37. Calandrella D, Romito LM, Elia AE, Del Sorbo F, Bagella CF, Falsitta M, Albanese A (2015) Causes of withdrawal of duodenal levodopa infusion in advanced Parkinson disease. Neurology $84: 1669-1672$

\section{Affiliations}

Leonardo Lopiano ${ }^{1} \cdot$ Nicola Modugno $^{2} \cdot$ Pietro Marano ${ }^{3} \cdot$ Mariachiara Sensi $^{4} \cdot$ Giuseppe Meco $^{5} \cdot$ Paolo Solla $^{6}$. Graziano Gusmaroli $^{7}$. Filippo Tamma ${ }^{8}$. Francesca Mancini ${ }^{9} \cdot$ Rocco Quatrale $^{10}$ - Roberta Zangaglia ${ }^{11}$. Annarita Bentivoglio ${ }^{12,13} \cdot$ Roberto Eleopra $^{14} \cdot$ Giuliana Gualberti $^{15} \cdot$ Gabriella Melzi $^{15}$ (D) Angelo Antonini ${ }^{16}$

1 Department of Neuroscience, University of Torino, Torino, Italy

2 IRCCS "Neuromed", Pozzilli, Italy

3 Casa Di Cura Madonna del Rosario, Raggruppamento Di Riabilitazione, Catania, Italy

4 Neurology Unit, Azienda Ospedaliera Universitaria Sant'Anna, Cona, Ferrara, Italy

5 Department of Neurology and Psychiatry (Parkinson's Centre), Research Centre of Social Diseases (CIMS), Sapienza University, Rome, Italy

6 Neurology Unit, Policlinico Universitario Monserrato, Cagliari, Italy

7 Neurology Unit, Ospedale degli Infermi, Biella, Italy

8 Neurology Unit, Miulli Hospital, Acquaviva delle Fonti, BA, Italy
9 UO Neurologia e Stroke-Unit e Laboratorio Neuroscienze, Istituto Auxologico San Luca, Milano, Italy

10 Neurology Unit, Hospital Dell'Angelo, Mestre, VE, Italy

11 Parkinson's Disease and Movement Disorders Unit, IRCCS Neurological National Institute C. Mondino, Pavia, Italy

12 Institute of Neurology, Università Cattolica del Sacro Cuore, Rome, Italy

13 Fondazione Policlinico Universitario A. Gemelli IRCCS, Rome, Italy

14 Fondazione IRCCS Neurological Institute Carlo Besta, Milan, Italy

15 AbbVie Srl, Campoverde, LT, Italy

16 Parkinson and Movement Disorders Unit, Department of Neuroscience, University of Padua, Padua, Italy 